
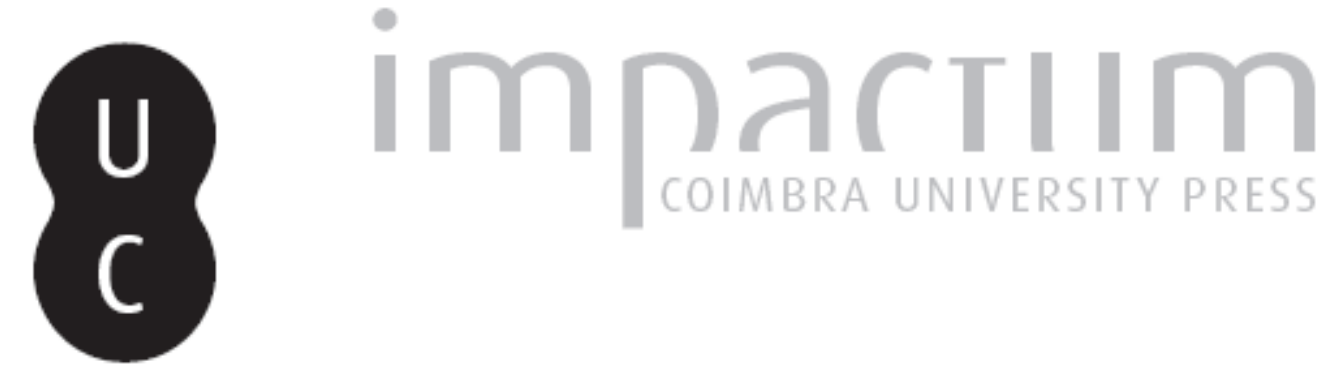

\title{
A ruína e a memória reprimida como estilos da cidade moderna: os trabalhos de Gordon Matta-Clark
}

Autor(es): $\quad$ Pousada, Pedro

Publicado por: Imprensa da Universidade de Coimbra

URL persistente:

URI:http://hdl.handle.net/10316.2/35516

DOI:

DOI:http://dx.doi.org/10.14195/0870-4112_11_18

Accessed : $\quad$ 26-Apr-2023 16:32:20

A navegação consulta e descarregamento dos títulos inseridos nas Bibliotecas Digitais UC Digitalis, UC Pombalina e UC Impactum, pressupõem a aceitação plena e sem reservas dos Termos e Condições de Uso destas Bibliotecas Digitais, disponíveis em https://digitalis.uc.pt/pt-pt/termos.

Conforme exposto nos referidos Termos e Condições de Uso, o descarregamento de títulos de acesso restrito requer uma licença válida de autorização devendo o utilizador aceder ao(s) documento(s) a partir de um endereço de IP da instituição detentora da supramencionada licença.

Ao utilizador é apenas permitido o descarregamento para uso pessoal, pelo que o emprego do(s) título(s) descarregado(s) para outro fim, designadamente comercial, carece de autorização do respetivo autor ou editor da obra.

Na medida em que todas as obras da UC Digitalis se encontram protegidas pelo Código do Direito de Autor e Direitos Conexos e demais legislação aplicável, toda a cópia, parcial ou total, deste documento, nos casos em que é legalmente admitida, deverá conter ou fazer-se acompanhar por este aviso.

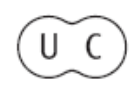




\section{ESTÉTICA E POLÍTICA}

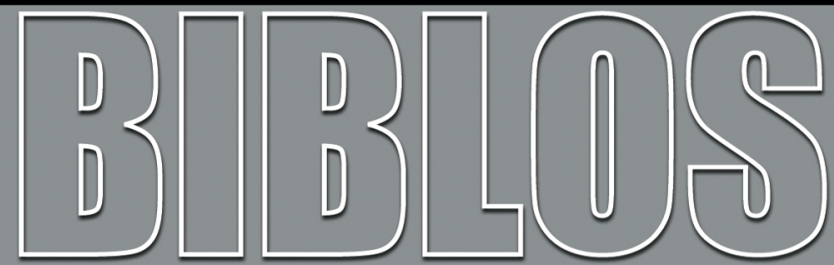

REVISTA DA FACULDADE DE LETRAS UNIVERSIDADE DE COIMBRA 
Biblos, n. s. XI (2013) 425-454

DOI: http://dx.doi.org/10.14195/0870-4112_11_18

Pedro Pousada

Departamento de Arquitetura da FCTUC

\section{A RUÍNA E A MEMÓRIA REPRIMIDA COMO ESTILOS DA CIDADE MODERNA: OS TRABALHOS DE GORDON MATTA-CLARK}

\section{Resumo}

O presente artigo resume uma investigação ainda em curso sobre um grupo variado de objetos site-specifics desenvolvidos por Gordon Matta-Clark (1943-1978) entre 1973-1978.

O meu interesse foca-se no modo como os seus trabalhos artísticos percepcionam e problematizam temas como o isolamento, o voyeurismo e o vazio urbano na conjuntura espaço temporal da modernidade tardia. Coloco também a hipótese de que o interesse de GM-C pela abertura cirúrgica de superfícies em edifícios abandonados, que o seu desempenho extractivo em torno da morte de um ambiente construído pretende dialectizar as ambiguidades visuais e semânticas que definem as duas principais concepções ocidentais de apropriação e transformação do espaço humanizado: uma que compreende e trabalha o espaço como uma entidade abstracta, como um tropo da geometria cartesiana, uma relação figura-fundo desligada da história, mas que na verdade se define historicamente como uma concepção mediada e construída pela estética ocidental, pela diferenciação de classes, pela serialização e pelas leis da propriedade e da burocracia. A outra abordagem configurando o espaço como uma construção antropológica e improdutiva. Uma construção fundada em processos metafóricos e onde a poética do sensível e as analogias visuais têm a sua retroactividade social e cultural.

Podemos contextualizar como agentes dessa dialéctica o seu corpo de trabalho posicionado entre os Bronx Floors (1973) e o site-specific parisiense Conical Intersect (1975).

Palavras-chave: Arquitectura, Arte Contemporânea, Modernismo, Ruína, Monumento.

\footnotetext{
Abstract

The present article sums up an ongoing research into an assorted group of site-specific objects developed by Gordon Matta-Clark (1943-1978). I tur-
} 
ned my scope into the way his works advance a perception of urban isolation, voyeurism and physical bareness in the space-time conjuncture of late modernity.

This article also argues that G.M-C interest on the concept of open building surgery and his extractive performance on the demise of a built environment explores the visual and semantic ambiguities that define the two chief western culture approaches surrounding the appropriation and transformation of humanized space: one takes space as an abstract entity, a trope of geometry, a figure-ground relation, but in fact mediating it through western aesthetics, class differentiation, serialization, property laws and bureaucracy. The other approach assumes space as an anthropological and non-productive construction. A construction based on metaphorical processes and where poetic and visual analogies have their social and cultural returns. We can clearly contextualize as subjects of this dialectic the derivative non-objects that range from Bronx Floors (1973) to the Parisian site-specific Conical Intersect (1975).

Keywords: Architecture, Contemporary art, Modernism, Ruin, Monument. 


\section{O espaço-tempo arquitectónico}

Gordon Matta-Clark cresceu rodeado de estaleiros de obras; um mapa da área de Soho onde habitava na sua infância e publicada no New York Times de Dezembro de 1957 onde se situavam as obras e desenvolvimentos em curso localizava uma das maiores obras mesmo à entrada da sua casa; esta era a Nova Iorque metamórfica descrita por Saul Below na sua novela Herzog, através da qual o seu herói epónimo peregrinava rodeado pelas piras incendiadas de edifícios demolidos, com as suas roupas e dos restantes pedestres marcadas pela sempre presente cinza.

JAMES ATLEE ${ }^{1}$

Anfião, filho de Zeus e Antíope teria, segundo a mitologia grega edificado com o som da sua lira parte da cidade de Tebas. $\mathrm{O}$ mito de Anfião é a narrativa de um fazer que se torna presença e materialidade. Essa narrativa serve de apoio à nossa investigação. A cidade, a sua vida e a sua morte, é feita por homens e mulheres e neles há o grupo dos que "para possuírem, fazem 2 ". Esse grupo tem múltiplas formas sociais sendo a dos artistas a que interessará a esta discussão.

A supertécnica artística ergue cidades ao mesmo tempo que é a sua autocrítica assomando-se como "a vingança das forças genuínas da existência contra a repressão da civilização ou da cultura ${ }^{3}$." Enquanto "práxis e ritualidade" " a arte realiza no espaço a mediação entre dois fenómenos que persistem, i.e, dois fenómenos históricos: o seu objecto, a obra artística (a duração qualitativa - o algo mais - de uma forma e de um comportamento que colocam entre parenteses a dimensão pragmática e utilitária do trabalho humano), e o "trabalho total social" dos

${ }^{1}$ James Atlee, Towards Anarchitecture: Gordon Matta-Clark and le Corbusier, London, Tate Papers, Spring 2007.

${ }^{2}$ Giulio Carlo Argan, História da Arte como História da cidade, São Paulo, Martins Fontes, 1998, p. 38.

${ }^{3}$ Giulio Carlo Argan, História da Arte como... cit., p. 16.

${ }^{4}$ Giulio Carlo Argan, Op. Cit., p. 39.

5 “O complexo dos trabalhos privados forma o trabalho total social.” In KARL MARx, O Capital, primeiro livro tomo I, 1. ' capítulo - A mercadoria, Lisboa, Edições Avante!, 1990, p. 88. 
arquitectos e construtores, a cidade. Ambos a obra e o muro circundante que a contém - a Polis- são afinal a mesma coisa observada de posições e momentos diferentes: o ser-no-tempo problematizando as ligações do seu arquétipo à sua acção presente.

Construir ou destruir, erguer ou montar, permanecer ou abandonar, despojar ou ornamentar, reiterar ou criticar são atitudes decisivas que moldam esse sistema de relações.

É um dos principais objectivos do presente artigo tentar analisar esse sistema de relações na óptica das artes plásticas tentando compreender como se operam no ambiente construído as relações de concomitância e de oposição entre dois mitos fundacionais da modernidade do século XX: a) o espaço-tempo como objecto do progresso intranscendente do construído (progresso cujo principal guia é a arquitectura e cuja principal condição histórica é a cidade, oximoro de abundância e escassez), e b) a subjectividade entendida aqui como uma construção social que encontra no artefacto arquitectónico o seu recuo curativo ou simplesmente a ilusão de um lugar blindado contra a alteridade.

Optamos por fazer esse trabalho, através de obras específicas do artista norte-americano Gordon Matta-Clark (1943-1978), porque não tendo sido, como adiante veremos, pioneiro no acto de se fixar no objecto arquitectónico e nos seus códigos foi, contudo, um dos primeiros a torná-lo (a ele e ao seus efeitos) no medium com que confrontou os fundamentos da ideia de obra e de experiência artística na cultura ocidental.

Malevitch, por exemplo, compreendeu, desde 1919, no início do seu período no SVOMAS em Vitebsk, até ao seu texto de 1928,"A pintura e o problema da Arquitectura" (Nova Generatsia, . $^{\circ} 2$ ) que a arquitectura (que Malevitch como antes Apollinaire no seu Meditations Esthétiques $(1913)^{6}$, subtraia ao nexo construtivo-utilitarista ${ }^{7}$ e a qualquer deter-

6 "O fim utilitário que propõe a maioria dos arquitectos contemporâneos é a causa do considerável atraso da arquitectura com respeito ao resto das artes. $O$ arquitecto, o engenheiro devem construir com intenções sublimes (...). In GuILlaume Apollinaire, Meditaciones Estéticas, los pintores cubistas, Madrid, La Valsa, Visor, 1994, p.85. Tradução do autor do presente artigo.

7 "Eu compreendo a arquitectura como uma actividade fora de qualquer utilitarismo, uma arquitectura não-objectiva (...).”, Kasimir Malevitch. In ANDERSON Troels, (Ed.), The Artist, Infinity, Suprematism: Unpublished Writings 1913-1933, Copenhaga, Borgen,1978, p.102. Tradução do autor. 
minismo ideológico), era a terra prometida da nova arte. A superfície plana e finita (o quadro) cedera o seu lugar ao espaço concreto (a fachada dos edifícios e finalmente a ideia de edifício-volume); o olhar aprisionado na pirâmide perspéctica fora substituído pelo icarismo da representação axonométrica (o sujeito afastara-se como um aeronauta de qualquer centralidade dramática). Esta passagem da apropriação pictórica do vazio (a representação do vazio) para a sua organização e controle através do objecto arquitectónico constituiu um importante impulso para a definição dos aspectos metodológicos da obra de Gordon Matta-Clark.

O Suprematismo chegara à forma arquitectónica com a introdução da abstracção na dinâmica espacial assim como a arquitectura chegaria, no seu processo de rejeição do eclectismo e do historicismo, ao espaço não-objectivo. As "arquitecturas cegas" de Malevitch como as descreveu Siegfried Gideon, os seus Architektons horizontais (Alpha, 1923) e verticais (Gota, 1923) e os seus Planitas, não só se reclamavam do espaço-tempo como constituiriam um tropo de resistência transhistórica (como uma tábua rasa ex-nihilo) e performativa (por via do formalismo das suas massas sólidas); aspecto que Selim Khan-Magomedov sublinharia ao comentar que Malevitch ajudara os arquitectos:

“(...) a ver de novo, a refrescarem a memória sobre a existência das superficies geométricas planas e das suas inesgotáveis possibilidades combinatórias em composições espaciais complexas e eficazes.

A justaposição de volumes nas composições arquitectónicas de Malevitch e nos Prouns de El Lissitsky geraram relações e dispositivos que raras ou nenhumas vezes tinham sido usadas para fins arquitectónicos: o deslocamento vertical e horizontal de volumes em relação um ao outro; um volume a pairar sobre outro, a colocação de uma superfície volumosa sobre outras mais pequenas e fragmentadas, a negação da simetria, uma abordagem original da gravidade, com a forma visualmente pesada colocada sobre a forma aparentemente leve. As ricas oportunidades oferecidas pela luz e pela sombra, as diferenças e contrastes de escala. A mudança constante da composição espacial conforme a deslocação do observador ${ }^{8}$."

${ }^{8}$ Selim Khan-Magomedov, Pioneers of Soviet Architecture, Nova Iorque, Rizolli 1987, p.64. 
As palavras de Magomedov por nós sublinhadas poderiam funcionar como epígrafe às excisões de Gordon Matta-Clark que fundamentam a nossa reflexão.

Numa leitura do modernismo que não coloque o acento em exclusivo na sua crítica à representação mas na indeterminação das suas fronteiras metodológicas (na crise do nome e sentido das coisas e das práticas), esta digressão mutuamente inclusiva entre os dois campos da arquitectura e das artes plásticas é credível e produtiva. Siegfried Giedeon denotaria esta ligação intersticial entre a acção desinteressada e a experiencia do espaço já em 1941 ao estabelecer um paralelismo entre o quadro L'Arlesienne (1912) de Picasso e o edifício da Bauhaus (1923) de Walter Gropius. Os artistas são capazes de se relacionarem com os diferentes fusos horários da arquitectura assim como os arquitectos conseguem encontrar no empiria artística modelos não tradicionais e anti-miméticos de problematizar o espaço. Ambos apropriam-se dos códigos mas sem necessariamente se interessarem ou assimilarem a mensagem por eles construída. Os jogos de linguagem, os modos de produção da imagem ou da forma tridimensional, as técnicas visuais aperfeiçoadas pelo modernismo, a montagem, a composição assimétrica, a desfamiliarização do objecto, a relação disjuntiva entre elementos (plásticos ou textuais), a analogia visual, o arcaísmo prematuro e a fetichização da tecnologia como ideologemas da modernidade, todos estes elementos foram (ou não) dissociados das suas finalidades para entrarem e serem partilhados nas práticas de ambos os campos disciplinares. Numa caricatura dessa deslocação pendular entre unidade na acção e separação programática podíamos recordar como as paredes brancas sonhadas por Adolf Loos ${ }^{9}$ servem para Fernand Léger pendurar um Mondrian ${ }^{10}$ desse modo sobredeterminando a aliança ente a indizibilidade do estético e a firmitas tecnocrática.

Inclusivamente aquilo que os artistas designam como arquitectura pode muito bem ser o seu contrário, isto é a sua camera obscura,

9 "Vede, o tempo aproxima-se. A plenitude espera por nós. Em breve, as ruas das cidades brilharão como muros brancos.” In Adolf Loos, Ornamento e Crime, Lisboa, Edições Cotovia, 2004, P.225.

10 "(...) para um pintor uma parede branca é uma coisa perfeita mas uma parede branca com um Mondrian é uma coisa ainda melhor.” In FERNAND LÉGER, Funções da pintura, Lisboa, Livraria Bertrand, s.d, p.127. 
podendo não estar inserida na definição que os arquitectos dão do seu campo disciplinar; o entre estar, o trânsito entre arché e construção não é lido pelos dois campos da mesma forma, enquanto para os artistas plásticos os arquitectos são os que constroem, erguem e determinam a natureza das relações espaciais do indivíduo com o vazio, para os arquitectos esse trabalho começa antes, eles pensam sobre o construir, eles colocam-se no campo daquilo que ainda não é verdadeiro sem ser falso inserindo na sua metodologia, no quotidiano das suas práticas esse retorno ontológico a um fazer mitopoético, a um fazer que mistura poien (o acto em liberdade) e techné (o acto normalizado). Essa imersividade do problema (o plano) na obra (o plano em acto) e desta no problema (na história) é tomada como essencial para o arquitecto.

Outro aspecto releva da concepção da vida (do viver da cultura material, neste caso, do artefacto arquitectónico) definida por ambos os campos. Se a alteridade é-lhes comum, se ambos assimilam que para o sujeito que vê, que se desloca, frui, vive e ocupa, é impossível a unidade do ato arquitetónico, sendo que o todo existe no estar em cada uma das suas partes, ou seja, a descontinuidade e diferença dos objectos é uma condição necessária à experiência do espaço, é, também, verdade que ambos lêem em diferentes comprimentos de onda essa diferença. Pelo menos desde o Manifesto Surrealista que os artistas se interessam por desvelar, o que os arquitectos não se cansam de esconder e desconectar: a dimensão orgânica dos edifícios, a sua vida vegetal, a sua condição de corpo que absorve e de estrutura excretiva assim como as implicações fantasmagóricas da vida e morte da cultura material. Parafraseando Giorgio Agamben ${ }^{11}$ podemos observar que num jogo de percepções e de "cesuras" a arte acentua a "vida vegetal", a vida desprovida de consciência no interior do construído, enquanto a arquitectura desvincula essa vida vegetal da "vida de relação" com o mundo exterior que adquire, aliás, no tropo arquitectónico uma importância fundacional. Essa atenção dos artistas em relação aos diferentes fusos horários da arquitectura pode também produzir-se não investindo directamente na entidade física da arquitectura, isto é num ambiente construído específico, num edifício em particular mas como Richard Nonas explicava

${ }^{11}$ Giorgio Agamben, $O$ aberto, O Homem e o Animal, Lisboa, Edições 70, 2011, p.27-29. 
a propósito da agenda do grupo Anarchitecture a que pertenceu, e a propósito de Gordon Matta-Clark em particular, "a arquitectura pode ser usada para simbolizar os aspectos coriáceos, intransigentes da cultura ${ }^{12}$ ", que se pretende enfrentar e "desconstruir."

Depreende-se, portanto, que a arquitectura não funciona para os artistas apenas como um estrutura material que pratica o espaço-tempo e onde se naturaliza a aliança entre sintaxe formal e tecnologia mas como uma poderosa metáfora da ideia de cultura e do modo como os indivíduos se relacionam com os objectos e os conceitos.

Veja-se, por exemplo, como a arquitetura moderna recobrou do sono historicista o espaço construído e habitado fazendo-o regressar à história, à história em acto, isto é, colocando-se no coração da tensão dialéctica entre o homem particular e inacabado, dividido (a quem quer servir) e uma humanidade inanimada (de quem é serva). Nesse acto que a une às outras atividades humanas, a arquitetura mediatiza-se como um lugar socialmente justificado, um lugar na hierarquia da História, situado num ponto pós-diluviano em que a tecnologia e a tecnocracia impõem a sua marca autoral sobre a cidade.

A sua presença (ou ausência) expectante tornou-se contudo, multidimensional e contraditória: imagem (maquete), que ainda não é objecto real (edifício); modelo mediador de uma realidade ainda não vivida; experiência inaugural de um novo tipo de percepção; contentor que é contido pelas violências da história e objecto em permanente metabolização até à sua intranscendência como ruína, (cabendo, hoje, nessa categoria o edifício doente) ou até à separação da sua forma da função a que fora predestinada; incorporando todos esses atributos a Arquitetura manifesta-se então como o realismo (derrisório ou sedutor) do objecto construído, objecto esse onde a autonomia artística e o Weltbildung (a construção do mundo) se tornam site-specific, com todas as suas "economias, culturas, materialidades e promessas de segurança. ${ }^{13}$ "

12 Richard Nonas em carta enviada ao IVAM, Agosto 1992. In Sem autor definido, Gordon Matta-Clark, Catálogo da Exposição,Valencia: IVAM Centre Julio Gonzalez, 1993, p. 374.

${ }^{13}$ Detlef Mertens, Open countours and other autonomies. In Rodolfo Machado and Rodolphe El-Khoury (Eds.), Monolithic Architecture; Munich and New York, Carnegie Museum of Art and Prestel Verlag, 1995.p.58. 
A crescente socialização da arquitectura como imagem reforçou a sua colonização pelos dispositivos de serialização e convencionalização intensificando, por sua vez, a sua dupla condição de superestrutura - de um modo ideológico e político de entender o espaço e o seu uso- e de produto de um fundamento económico - a supremacia do valor de troca em relação ao valor de uso do espaço.

A codificação da Arquitectura como a organização logocêntrica e estética do espaço, tornou-se ao longo do Século XX o epicentro de uma interrogação fundadora: A quem pertence o mundo? Nesse questionamento a própria arquitectura adquiriu um deslocamento ontológico (O que é realmente? Para que serve? Quem serve? Quem a faz? Quem determina o seu valor de uso?). Esta consciência temática e multidimensional - a arquitectura funcionando como um compendium de um mundo historicamente determinado - constitui um dos atractivos que levam cada vez mais os artistas que se debruçam sobre as questões espaciais a utilizarem o ambiente construído, a memória e a transformação da experiência em imagem, como fontes primárias das suas incursões visuais. A lista dos que tem involucrado o seu corpo de trabalho na problemática do espaço arquitectónico é imensa e heteróclita mas podemos nomear como exemplos mais prementes e actuais os artistas Rodrigo Oliveira, Pedro Reyes, Gregor Schneider, James Casabere, Doménec, Natasha Randall, Ângela Ferreira, Nuno Sousa Vieira, Carlos Bunga, Didier Fiuza Faustino, Andrea Zittel, Monika Sosnowska ou os colectivos holandês Atelier van Lieshout e cubano Los Carpinteros.

\section{Preâmbulo Nova-Iorquino: Gordon Matta-Clark ou artista- -cirurgião do espaço como alternativa à automatização do arquitecto corporativo}

No seu best-seller Delirious New York- A retroactive Manifesto for Manhattan (1978) Rem Koolhas empreende uma peregrinação filosófica em torno de Manhattan definindo como principal causa objectiva do êxito visual e físico da ilha-cidade o facto desta se ter organizado num complexo de grelha/bloco definido por doze enormes avenidas entrecortadas por cinquenta e cinco ruas; esse facto sistémico favoreceu segundo ele a expressão plena do "ego urbanista", (urbanistic ego) e a conjunção dos valores de inovação e receptividade na sua tipologia mais 
duradoura, o Nysky (New York Skycraper). A permanência e banalização de uma unidade máxima de ocupação espacial, o bloco, no espaço da cidade-ilha significou que diferentes formas e funções se nivelavam no mesmo tipo de unidade. Na serialização do espaço, na compressão do projecto arquitectónico aos limites de uma quadrícula, havia promessa de felicidade criativa e de invenção plástica enciclopédica.

A sua principal tese é que a Nova Iorque de finais de 70, falida, com serviços públicos cada vez mais inanes, a filha decrépita de Robert Moses, é a sobredeterminação da liberdade (arquitectónica) dentro do controle (administrativo e social); esta é a a mesma cidade onde Marshall Berman inicia seu levantamento crítico sobre a solidez polínica da modernidade e da modernização fáustica.

A "cidade oximoro" (como a define Hal Foster ${ }^{14}$ ), do "caos rígido" e dos episódios arquitectónicos contraditórios é celebrada por Koolhas como metáfora espacial da modernidade baudelairiana: a instabilidade e o permanente sobrevivem na igualdade repetida da grelha. É na grelha que, para Koolhas, o heroísmo do presente se manifesta produtivamente.

Essa estranha forma de liberdade arquitectónica apodera-se " $d a$ escada (...) para o Universal"15. Torna-a mutante, diferente conforme vamos avançando nas fatias quilométricas da ilha de Manhattan, conforme nos vamos aproximando da cordilheira central. E com esse uso acentua o anti-mimetismo e o posicionamento contra-natura dos modernos “American Golias" em relação ao carácter narrativo, "storytelling”, da cidade histórica.

Perante a fantasmagoria e a memória do vivido no ambiente construído da metrópole, sobredetermina-se um novo dispositivo arquitectónico (o irredutível Nysky) destinado a fazer "explodir o mercado imo-

${ }^{14}$ Cf. Hal Foster, Bigness, retirado de http://www.lrb.co.uk/v23/n23/hal-foster/bigness, última consulta 10/6/2013. Este tema é desenvolvido também em HAL Foster, Rem Koolhas-From Manhattan to the city of exacerbated difference. In PETER BROOKER, and ANDREW TACKER, Geographies of Modernism, New York:Routledge, 2005, p.146-147.

${ }^{15}$ Para usarmos a definição que Rosalind KRAuss nos fornece das dissonâncias materialistas/idealistas do conceito de grid (grelha) no modernismo de Mondrian e Malevitch. In Rosalind Krauss, Grids, October, Vol 9 (Summer 1979), Cambridge, Massachusetts, The MIT Press, p.52. 
biliário ${ }^{16 "}$ tornando esmagadora a alienação do espaço pelo tempo; por um processo de substituição esse mesmo dispositivo clarifica que na vida quotidiana os edifícios já não são emblemas de um poder, objectos de pura contemplação, mas instrumentos activos na propagação e definição espacial desse poder.

O edifício torna-se ele próprio um estilo de vida. A uma estética passiva e descritiva que maravilha-se e torna solene a passagem do tempo, isto é que vê na construção e modernização das cidades um momento de afirmação e de catarse colectiva sucede-se outra onde a experiência múltipla do choque anda de mãos dadas com a dissociação trágica entre o sujeito e o espaço em que vive e trabalha: a cidade não acolhe mas ignora o sujeito que chega, a cidade não se revela mas aliena o sujeito que a tenta perceber.

O idealismo encomiástico de Koolhas define Nova Iorque como um prontuário onde a funcionalidade, a criatividade e a supremacia demiúrgica do arquitecto ainda aparentam ser plausíveis mesmo que o colete esteja apertado e a atmosfera irrespirável; onde é bela e apaixonada a aliança do grande Mogul da modernização pós-fordista, Wall Street, com a Grande Arte (incluindo-se nela, a arte dos arquitectos que não desistem de serem artistas e que se põe à procura de um novo alter ego para se recomporem das intempéries sociais que se tinham abatido sobre o modernismo europeu).

A financeirização da economia norte-americana e o seu futuro derrame mundial impregnaram a vida útil do corpus arquitectónico nova-iorquino e esse facto surge como uma oportunidade a não perder. Ora o que em 1978 Koolhas diagnostica como produtivo no trepidante e protoplasmático maneirismo "clean-drawn (...) clean-countoured (...) good-design ${ }^{17}$ " da arquitectura corporativa pró e pós miesiana tinha sido, dez anos antes, em 1968, num artigo publicado na revista Newsweek, objecto de análise e de inquietação por parte de Buckminster Ful-

${ }^{16}$ Manfredo TAfuri, The Sphere and the Labyrinth, Avant-Gardes and Architecture from Piranesi to the 1970s, Cambridge, Massachusetts, The MIT Press, 1987,p. 174.

${ }^{17}$ Clement Greenberg, Recentness in sculpture. In Gregory Battcock, Minimal art: A critical Anthology, Berkeley: University of California Press, 1995, pp. $180 \& 184$. 
ler ${ }^{18}$ que descreve a mesma Nova Iorque como uma falange de "giant, graveyard like, fire proof clusters. ${ }^{19}$ "

Entre a resignação e a dissidência B.Fuller argumenta que a soberania autoral do arquitecto é uma miragem na indústria automatizada da construção civil que se tinha apoderado de Nova Iorque desde os finais de 1940. Auxiliado por um catálogo de convenções e de aparatos construtivos normalizados (o Sweet Development Index, para os Estados Unidos), o promotor imobiliário e o seu cliente podiam facilmente ditar a sua visão e o seu individualismo libertário e pragmático (versão Wall Street) ao arquitecto; o individualismo faustico, o desejo de imortalidade e de originalidade através da ruptura artística, (o milenarismo da revolução estética romântica convergindo para a "hiperobjectividade americana ${ }^{20 "}$ ") já não são temas filosóficos presentes e urgentes na agenda do arquitecto que está já preenchida por códigos preconcebidos de construção, leis complicadas de zonamento, assim como por todo o tipo de restrições impostas pelos sindicatos da construção e por outras organizações laborais; inclusivamente deixou de ser um middleman tornando-se apenas, um salesman, um comerciante para quem as dialécticas do conflito social e formal estão fora do seu campeonato, para quem a iniciativa do desenho preliminar, primordial tornou-se uma memória longínqua; sobra pouco espaço para o papel do arquitecto como um inventor espacial e um inovador formal; tanto a experimentação como a especulação artística já não são elementos activos nos ateliês de arquitectura onde a taylorização tomou o poder.

Esta longa dissertação sobre as leituras possíveis de Nova Iorque (Koolhas versus Fuller; a cidade-autor versus a cidade sem autor) tem como objectivo situar o sujeito da nossa história, Gordon Matta-Clark.

Ele foi um nativo de Nova Iorque, e experimentou em directo o permanente ciclo de destruição/construção da cidade naturalizado pelo vínculo jurídico-administrativa mas também através dos seus avatares estéticos, (a cidade em acção como falsa consciência por via da publicidade, da comunicação de massas, das feiras internacionais e mundiais,

${ }^{18}$ Buckminster Fuller, Architecture state of the art today. In Architecture: a global report; Newsweek, May 27,1968, p. A3.

${ }^{19}$ BuCKMinster Fuller, Architecture state...Cit., p.A3.

${ }^{20}$ Adolf Behne (1923) apud Manfredo TAfuri, The Sphere and the... Cit., p. 175. 
da literatura, do cinema e da televisão) e sobretudo através da experiência incompleta e casuística dos seus habitantes.

Assim como experimentará, com a demolição compulsiva do bairro Radio Row no Lower East Manhatan e a subsequente construção das Twin Towers do WTC, (situações com as quais conviveu enquanto nova-iorquino no período entre 1966 e 1973), o clima de capitulacionismo arquitectónico (a evidência do "global sameness") que se pressente nas observações de Fuller.

Arquitecto formado na Universidade de Cornell (Ithacca, Nova-Iorque), onde terá sido, no período de 1962-1969, um estudante irregular (mas acima da média), G.M-C nunca exerceu a actividade para qual foi treinado. E se a exerceu foi num sentido circunvizinho do fragmento, do inacabado e do conhece-te a ti próprio ${ }^{21}$; e foi-o também segundo um tropo estranho às ambições performativas da arquitectura moderna: igualando a arquitectura à insignificância cosmogónica do lixo (ambas com um destino recíproco), observando-a na sua condição de ruína e de sólido a abater; redescobrindo uma antropologia do reprimido, do inconsciente no objecto negado, praticando uma metodologia quase ilegal (o cutting-out) para revelar um objecto mutante desprovido de qualquer sumptuosidade e de qualquer expectativa futura, um objecto finito de que já se sabe o seu ponto de saída: o esquecimento e a demolição. Não é de somenos importância o ethos surrealista que Gordon Matta-Clark extrai do convívio com o seu pai o pintor chileno surrealista Roberto Matta-Echaurren, também ele um arquitecto diplomado que optou pela pintura.

Conhecedor do pensamento corbusiano que não só estudou em Cornell segundo a batuta de Colin Rowe (que, nas suas aulas, definia Le Corbusier como a emulação moderna de Palladio. A Cornell School of Architecture ficou aliás conhecida na década de sessenta como Académie Corbu) mas também pelo facto de nos finais da década de trinta o seu pai ter trabalhado no atelier do arquitecto franco-suiço, G.Matta-Clark posicionava a sua análise (e intervenção) modernista do espaço urbano nos antípodas desse pesquisador saint-simonista da cidade moderna e dos seus acólitos norte-americanos. Mas como chega ele

${ }^{21}$ Cf. Spyros Papapetros, "Oedipal and edible, Roberto Matta Echaurren and Gordon Matta Clark”, in Elisabeth Sussman (ed.), Gordon Matta Clark - You are the Measure. New Haven: Yale University Press, 2007, p. 71. 
a esta antinomia que aliás não é absoluta ou não fosse possível ver a Façade Libre e o Plan Libre, a desmaterialização do espaço fechado, a supressão das paredes de suporte, manifestando-se em experiências como Bingo, Office Baroque ou Conical intersect? Como não reconhecer nestas suas duas obras a combinação dialética tão cara à arquitetura modernista entre "paredes transparentes" 22 (grandes fenestrações libertando e iluminando o espaço interior) e "paredes de imagens" (a ambiguidade fenomenológica entre a fachada e o que ela esconde ou revela, o interior, expondo-se e mediatizando-se na própria superfície dos edifícios)?

O diálogo de Matta-Clark ${ }^{23}$ com as pregações agonistas de Le Corbusier, em particular as que se definem no seu Vers une Architecture (1923) teve um carácter diferido, ripostando através dos puns, da escrita snapshot (muito ao estilo de Marcel Duchamp) e dos jogos de linguagem que colonizavam os apontamentos sobre os seus projectos, a sua correspondência e as notas que tomava para consolidar as suas ideias. Mas apesar do recorrente alvo em que se tornara a complexidade criativa de Le Corbusier para inúmeros grupos de vanguarda desde o anti-jansenismo espacial do grupo surrealista liderado por André Breton aos internacionais letristas que na década de cinquenta o apostrofaram de Le Corbusier sing-sing, ele não pode ser excluído dos processos de trabalho de Matta-Clark.

A presença deste espectro leva-nos aliás a outra interrogação: podemos ignorar o efeito que o doutrinamento heterodoxo dos seus primeiros anos letivos teve no seu trabalho futuro?

Dissidência é uma palavra que surge quando damos conta que a desencarnação parcial e cirúrgica de edifícios mortos foi realizada por alguém treinado para organizar e construir espaço, para problematizar o vazio, para montar os materiais de um modo coerente e performativo, para garantir o conforto e a inteligibilidade intra-muros necessárias para que a cultura, a economia e a família pudessem continuar as suas próprias conquistas.

A História da Arte do Século XX demonstrou-nos que tudo o que foi quebrado, desmitificado pelo modernismo foi obra de quem apren-

\footnotetext{
${ }^{22}$ Beatriz Colomina, Media as modern architecture. In Thomas Demand. London: Serpentine Gallery, 2006, p. 22.

${ }^{23}$ J AMES ATLEe. In Towards Anarchitecture... Cit, p. 11.
} 
deu a ser um crente e um especialista para poder ser um herético e um amador; alguém que antes do seu regresso adâmico, da sua rejeição da representação mimética, da sua busca pessoal por esse momento ontológico em que a Arte ainda estava despida das suas convenções, estudou o inimigo, foi o inimigo e viveu as suas ilusões. O conceito de vanguarda pode ser lido aliás como uma radicalização do conceito de paideia: educar para construir uma consciência das insuficiências humanas e uma cultura do inconformismo. O ethos das vanguardas é que as respostas erradas e desobedientes ajudam o conhecimento. Aprender é um acto desconfortável, afasta o sujeito das suas certezas (da norma, do estereotipo), desampara-o do modo como se habituou a estar e a representar o mundo. Isto significa que a arquitectura não foi em Gordon Matta-Clark um mero aparato sobre qual reagiu. Essa relação não se restringe a uma mera questão posicional mas nas suas acções, nos códigos (alquímicos, antropológicos, neo-primitivistas, cubistas, surrealistas) com que constrói o seu sistema de crenças (sobre a arte, sobre a cidade, sobre a vida e a condição moderna) ele manifesta essa reflexividade (do discurso arquitectónico) que vai evoluindo para uma inversão, como um indivíduo que depois de aprender a conduzir um automóvel transforma-o numa bicicleta.

No ano de 1964, ano em que Gordon Matta-Clark interrompeu os seus estudos em Cornell, Bernard Rudofsky foi o responsável curatorial no MoMA pela exposição "Arquitetura sem Arquitetos “- foi GM-C um visitante desse evento? Se sim, quais foram os impactos e questionamentos sobre o papel da cultura popular na produção do espaço? Será que como Derain e Picasso no Trocadéro, em 1908, maravilhados com a plasticidade e força visual da escultura africana, ele não se interrogou se estes não eram os autênticos processos de produção e uso do espaço?

Estas (nossas) interrogações que justapõem a geografia e a história da produção de espaço em planos equivalentes levam-nos a propor que na obra de Gordon Matta-Clark a arquitectura posiciona-se como uma mnemotécnica do humano. O modernismo foi um processo intensificador dessa mnemotécnica: o exterior pitoresco que se torna uma potência doméstica e sobre o qual se projecta uma atenção contemplativa -le dehors est un dedans como no slogan corbusiano; a quadrimensionalidade do cubismo sintético transformado em transparência e interpenetração de vazio e cheio no edifício bahausiano ou na translucidez desorientadora do Pavilhão de Barcelona; a visão androcêntrica do lar 
burguês: Observatório e Fotogenia como nas moradias corbusianas; Domus Teatrum como nas casas burguesas do austríaco Adolf Loos ou ainda o voyeurismo vático do aquário miesiano da casa Farnsworth (a exposição e a intangibilidade do edifício são mutuamente inclusivas: o edifício vê-se a ser visto e ao mesmo tempo mantem-se distante do corpo que o vê) ${ }^{24}$; a funcionalização da rua como espaço de rapidez e de produção, o conceito de zonamento, e a imersão do cidadão apenas como coisa na estetização da paisagem (a escultura humana circula no parque afastado da autopia que o ameaça e que ele atrapalha); todas estas referências dirigiram-se como norma e como empiria para a mesa de estirador onde Gordon Matta-Clark começou a aprender a ser arquitecto para poder ser outra coisa.

Ele assimilou-as e exorcizou-as como especificações da produção do espaço moderno que, apesar da sua fotogenia, apesar da sua aparente eficácia em tornar verosímil o reino da estética apenas conseguiam acentuar a sensação de incompletude e de desacordo entre o papel e a realidade construída da cidade e de uma cidade em particular, Nova Iorque.

Beatriz Colomina ${ }^{25}$ afirma, aliás, que o principio activo da existência do artefacto arquitectónico moderno, aquilo que mobilizou o seu estar no mundo situou-se no âmbito da experiência diferida, na fotogenia daquilo que aconteceu e que quer ser visto ou na simulação daquilo que não aconteceu mas que é materialmente possível (e desejável) que aconteça. Gordon Matta-Clark, argumentaremos, entenderá que esse posicionamento no âmbito da imagem ${ }^{26} \mathrm{e}$ da persuasão estética, i.e, no ficar bem antes de tudo na fotografia, na imagem impressa, teve graves custos ideológicos.

Se em Le Corbusier, Gordon Matta-Clark encontrou um nemesis simbólico, o seu verdadeiro condensador filosófico, a sua escola cultural e política seria a resistência cívica que as comunidades de bairro da Lower Manhatan, de Greenwich Village, do Soho de finais de 50 e da

${ }^{24}$ Cf. Beatriz Colomina, The Split Wall: Domestic Voyeurism, In (Ed.) Sexuality and Space, Princeton: Princeton Architectural Press, 1992,p. 73-128.

${ }^{25}$ Beatriz Colomina, Media as modern... Cit. In Thomas Demand. London: Serpentine Gallery, 2006, p.22.Cf. Beatriz Colomina, Doble exposición: alteracion de una casa suburbana (1978), Madrid: Ediciones Akal, 2006, p.197-199.

${ }^{26}$ Beatriz Colomina, Doble exposición: alteracion...Cit, p. 199. 
década de 60 encetaram contra as imposições políticas de realojamento e de auto-estradização do Comissário do Planeamento Urbano, Robert Moses.

Uma luta material cujo conhecimento de causa ele adquire no final da sua adolescência (enquanto vizinho quotidiano de muito dos activistas e das iniciativas por eles organizadas); foi, então, na aprendizagem e descoberta de um espaço utópico que emerge não tanto de uma construção ideal, de um plano mas que é definida por uma lógica de "inclusão disjuntiva" que assimila ao ethos da cidade não só a essência dos seus limites, do que as suas leis e os donos dessa leis podem realizar sobre o seu corpo mas que configura e torna tangível a escala e os intervalos com que os indivíduos se relacionam entre si no seu espaço.

$\mathrm{Na}$ distribuição dos seus poderes a cidade descobre um que se enraíza não tanto nas leis espaciais, na imposição física de um modo de ser mas num poder que nasce e se desenvolve através da percepção de que o espaço do quotidiano, dos costumes e vivências é frágil e perecível perante a modernização e que só no agir e no questionamento político de "uma maneira melhor de fazer e de existir" é que a condição de estar livre se pode tornar na condição de estar livre num lugar determinado e de que é a mundanidade desse lugar, o que ele já viveu, o hábito e a passagem do tempo, e o que ainda pode viver, a descontinuidade histórica, que interessa sobredeterminar como identidade do espaço.

Claramente esta concepção é antagonista do "ego urbanista" de que falaria Koolhas e da monetarização do espaço que lhe é afim. A história de Nova Iorque ainda é maioritariamente definida por esta macro-política, "capital acumulado ao ponto em que se torna arquitectura", cuja imagem inefável é o Sky Craper, Mas isso não significa que a cidade que se constrói como regime dos polloi (dos muitos) e que se constrói a partir do desejo de tornar inteligível para quem se faz espaço e se altera o espaço, não tenha feito (não faça como agora temos visto com o movimento Occupy Wall Street) as suas incursões na história metropolitana.

Foi proporcionado originalmente por esse ambiente humano solidário (a de que os cidadãos tem algo a dizer e a fazer sobre a cidade em que vivem e trabalham) que Gordon Matta-Clark viria a escorar, mais tarde, o seu ressentimento ideológico e cepticismo conceptual em relação aos erros de cálculo do genial e impaciente suíço-parisiense; erros cuja expressão consumada era a cidade planificada e, também, a cidade da expropriação compulsiva onde o culto festivo do futuro e da 
eternidade perdurava como tema (e negócio) dos especialistas e onde o arquitecto se tornava cada vez mais um mero lojista.

Erros que ecoavam nos projectos derrotados (mas também nos realizados, como nos recorda Marshall Berman) de R.Moses tais como a extensão da Quinta Avenida que atravessaria e destruiria o Parque da Praça de Washington (perto de onde, aliás, se situava a Judson Gallery onde Claes Oldenburg, Jim Dine fariam as suas primeiras instalações), o LOMEX, a Via rápida de dez pistas com que Moses pretendia ligar a ilha a New Jersey e a Brooklyn e que significaria a terraplanagem de uma importante área habitada do Soho nova-iorquino: restringir a concepção e o uso criativo do espaço às regras do controlo social; extinguir a rua, a vida de comprido e com isso abstractizar a experiência e a escala do espaço urbano moldando-a à perspectiva do espelho retrovisor; acentuar a não participação do cidadão comum na temporalidade da cidade; limitar os autores da cidade, limitar a aventura da exploração do possível humano da cidade socialmente densa e culturalmente heterogénea, aos especialistas.

O activismo de Gordon Matta-Clark ingressava numa concepção inclusiva, comunitária do espaço da cidade; uma concepção que se debruçava, tacticamente, sobre a realidade concreta da Nova-Iorque dos anos 70, nas "ordens e desordens dinâmicas da cidade ${ }^{27}$ ", procurando nos despojos, nos materiais/objectos/edifícios sobrantes dos processos de modernização/destituição da metrópole, oportunidades para contornar o vínculo money begets property begets modernization regido pelo direito privado burguês e pela dominação burocrática ${ }^{28}$.

Nessa trabalho de recuperação e redesenho do lixo da cidade entrevia a oportunidade de realinhar os habitantes, os inquilinos e os frequentadores do Lower East Side (e as suas organizações de bairro) como elementos participantes na (re)construção proprioceptiva, vivida dos seus espaços de existência.

A itinerância ideológica e o radicalismo cinético dos seus cortes (em que o espectador/cidadão passa de figura inócua no pano de fundo do espaço construído para a de figura sobreexposta e reactiva à figura do espaço construído) circulam entre a ideia da Cidade para todos e o

\footnotetext{
27 James AtLee, Op. Cit., p.11.

${ }^{28}$ Jurgen Habermas, Técnica e Ciência como Ideologia, Lisboa: Edições 70, 2001, p. 45 .
} 
da Cidade feita por todos; e nesse trânsito sobressai que a transparência, o arranha-céus de vidro, a casa de vidro, a visibilidade extrema como tropo arquitectónico moderno alimenta uma falsa generalização das classes sociais; para G.M-C a modernidade arquitectónica tornara-se a imagem distorcida, cache-misére, da igualdade social.

\section{Sobre a cirurgia de edifício aberto de Gordon Matta-Clark}

A parte fundamental da produção de G.M-C, aquela que solidariza o intervalo de tempo compreendido entre Bronx Floors, 1973, W-Hole House, Genoa, 1973 (mas em particular a partir da sua obra manifesto Splitting, 1974) e que finaliza no projecto Circus or the Caribbean Orange, (1978), concretizar-se-á na atmosfera híbrida de Nova Iorque e dos seus arredores metropolitanos, em particular na Grid de Manhattan onde o culto do ornamento e o disparate de estilos que vai do gótico da Catedral de Saint Patrick ao neo-romano do New York stock Exchange, se cruzam com o deserto-mundo não objectivo de serialização infinita, de indistinção e de transparência onde as ruas brancas sonhadas pelos puristas modernos estão esmagadas pelos signos comerciais e "comidas pelas palavras".

É nesse espaço esquizóide, eriçado, em que, como já o pressentira Baudelaire, a cidade natal tornou-se irreconhecível, inabitável, transformou-se num teatro e num país estrangeiro, que ele começará a sua obra performativa, multidimensional, a sua arquitectura aforística e digestiva; vertigem trágica do colapso, da desorganização; pronunciamento dos poderes significantes e encantatórios dos materiais.

Com efeito apesar de Génova, Paris, Antuérpia e Chicago terem providenciado a matéria - prima (edifícios devolutos) para os seus building cuts é na sua cidade natal que é mais quotidiano e premente o conflito entre finitude e ruptura, entre a dor social que se incrusta na superfície arquitectónica (e que se ousa mostrar) e o idealismo da tábua rasa. É aí que na extensão das suas avenidas a cidade é lida como o lugar de um crime civilizado, de um eterno retorno planeado em que tudo, o espaço habitado, o espaço em ruínas, os espaços vividos e os não-lugares, os interstícios e os canais demóticos são mero terrain vague, indeterminações aguardando passivamente, obedientemente a sua secularização como obsolescência, como oportunidades de negócio pela aliança entre 
o empreendedorismo imobiliário, a alta finança e os gabinetes de arquitectura. É nela que a arquitectura como imagem das descontinuidades das sociedades funciona em tempo real.

Porque se o visível, o espaço construído, é aborrecido e vazio (ou esvaziado à força), se nele concretiza-se a aprendizagem do conformismo, a naturalização do planeado como inescapável (o fecho de uma fábrica, o fim de um negócio, a morte da rua como estilo de vida, a destruição de uma comunidade) é nele também que podemos encontrar a porta estreita por onde os que sucumbiram, e já não apenas os homens sobrenaturais, os heróis do capitalismo, se fazem ouvir. As excisões arquitectónicas de Gordon Matta-Clark são algumas dessas portas. Com efeito a acção cirúrgica que acelera a entropia do edifício, e a imagem desfocada do que ele foi como espaço do vivido, são mobilizados para transformarem o destroço arquitectónico numa imagem dialéctica, na representação do antagonismo entre o eterno (o monumento) e o efémero (a mercadoria) e desse modo acentuarem as diferenças ideológicas e materiais entre um dever ser da cidade baseado na vontade dos governados e um ter que ser da cidade decidido pelos governantes. Ao realismo do poder efectivo do dinheiro ele contrapõe o híper realismo de um objecto que na sua própria negação, na sua ruína, era restabelecido e reintroduzido nas relações de força da vida urbana; e era-o por via de um sujeito capaz de colocar o conhecimento em acto, de se assumir como operador de uma crítica dessa reprodução incessante da cidade, operador de uma crítica capaz de arriscar. Gordon Matta-Clark tem plena consciência que todas as cidades são espaços de negatividade poética e performativa, isto é, são a destruição criativa em acto; essa desconexão, (tudo cessa, interrompe-se, desmantela-se), está presente na sua estratégia subtractiva. A sua crítica não se dirige a essa condição inescapável das actividades humanas, a mudança, mas ao modo como as comunidades são separadas, excluídas da sua história.

Há vestígios gramscianos nas acções de Gordon Matta-Clark: os tiros disparados sobre as janelas do Institute of Architecture and Urban Studies no contexto do projecto Windows Blow out (1976) em que expõe uma série fotografias de edifícios vandalizados na zona do Bronx constituem algo mais do que um acto de provocação. Matta-Clark utiliza o acto mimético (copiando o comportamento destrutivo da marginalidade do Bronx) para assinalar dois aspectos do mesmo impasse metodológico e conceptual da arquitectura moderna: a incapa- 
cidade de desnaturalizar o barbarismo das relações de força no espaço urbano e a passividade efectiva em que, na sua perspectiva, o arquitecto enquanto sujeito social, mergulhara desde que no seu Vers une Architecture (1923), Le Corbusier propusera substituir a revolução pelo platonismo de uma arquitectura plenipotenciária e fazedora de mundos, ou dito doutro modo propusera uma forma melhor de existir para que tudo ficasse na mesma.

É o edifício metabolizado, o edifício que se contextualiza, literalmente, com a cidade (através das subtracções, dos vazios criados pelo esforço físico) é a arquitectura que atingiu, parafraseando Gordon Matta-Clark ${ }^{29}$, a sua exaustão social, quem melhor reflecte o anti-plano, a irracionalidade de um processo de deliquescência dos objectos, do seu caminhar para o nada.

Para além da sua vontade de introduzir movimento, instabilidade, de acelerar a presença do declínio em estruturas estáticas há, no corpo de intervenções de Gordon Matta-Clark, uma vontade mimética de se ligar, através do esforço físico pessoal, das horas de isolamento, fechado com os seus escassos colaboradores, nos espaços que desmantela, no plano de acções, onde intuição e organização são muitas vezes convergentes, na carga horária exigida pelo que se propõe realizar, na manufactura por vezes amadoristica e onde a força de vontade se sobrepõe ao conhecimento especializado das ferramentas e dos materiais, há em tudo isso uma imitação (deliberada ou não) da ética de trabalho da mão-de-obra intensiva que outrora ocupara esses espaços como locais de produção ou como locais de existência familiar. Mas um mimetismo festivo onde o artesão se junta à comunidade através das complicações legais do seu gesto (que o levam aos tribunais, às páginas dos jornais, ao exílio voluntário, à incompreensão dessa mesma comunidade); ou que o leva a criar espaços alternativos e outras situações ambíguas: a cantina para artistas, Food, aberta em 1971 sobre os restos mortais de um restaurante de comida crioula, situado na Soho nova-iorquina; ou, ainda, divulgando entre o seu grupo de afinidades as sucessivas experiências com alimentos incomestíveis, criações de tecidos de vida dormente, que fazem ressaltar o carácter metabólico da vida e que resultam

${ }^{29}$ Cf. Pamela M. Lee, Object to be destroyed, Massachusets: MIT Press, 2003. Em particular, o capítulo 4, On the holes of History, p. 162-168. 
de uma conjugação bizarra entre gastronomia neo-primitivista (back to the basics) e especulação alquimista, Photo-Fry, 1969, Agar Pieces, 1969-70, Incendiary Waffers, 1970-71.

Não podemos contudo falar de Gordon Matta-Clark sem destacar a influência original de Robert Smithson (1938-1973) no desenvolvimento do seu pensamento artístico. Com certeza que sem R.Smithson existiria um Gordon Matta-Clark mas não seria aquele que ficou para a posteridade. Já referimos Le Corbusier infamado como o pai fundador de todos os males da arquitectura construída, Smithson será o outro contrapeso que o marcará. Essa influência começa no Campus da Universidade de Cornell na montagem da exposição EarthShow (1969) organizada por Willoughby Sharp e que, na dezena de artistas convidados, contaria com nomes significantes como Robert Morris, Dennis Oppenheim, Jan Dibbets, Hans Haacke e o referido Robert Smithson; uma das primeiras exposições em que se introduz o conceito de site-specific em que os artistas eram questionados a não colocarem na superfície dada um objecto concebido a priori mas a desenvolver uma proposta em diálogo com a fenomenologia do parque de Ithaca, e que, de algum modo fosse concomitante com as propriedades e contingências da topografia em questão; uma exposição, afinal, em que o estudante de arquitectura Gordon Matta-Clark passou de diligente colaborador da plêiade de Land-artists (trabalhou mais intensamente com Dennis Openheim) que ai se apresentou, a promitente activista artístico.

Um dos aspectos que mais se destacou dessa troca recíproca de ideias e sobretudo dessa amizade foi o que implica ser artista para R.Smithson. Como muitas outras gerações de modernistas a de R. Smithson tentou apresentar a sua hipótese de superação da velha dualidade que no mundo das artes da visão separava a vida teórica (no sentido do étimo grego, théôrètikos, contemplação, observação, estudo, análise, definição de um método, de um fio no labirinto ${ }^{30}$ que permitisse sempre ao artista quando se perdesse reencontrar o caminho de volta)

${ }^{30}$ Roland Barthes fazendo referência a Gilles Deleuze: «Método: segundo Deleuze: Meio para evitar que nos desloquemos a determinado local, ou para garantir a possibldade de conseguirmos sair desse local (o fio no labirinto)».In Roland Barthes, Comment Vivre ensemble, Cours et séminaires au Collège de France (1976-77), Paris: Traces écrites, Seuil Imec, 2002, p. 33. 
da vida prática, (isto é do activismo, da jornada criativa enquanto luta entre imaginação e burocracia).

É nesse sentido que Robert Smithson procura dar um carácter conceptual e cognitivo à sua produção e que se aplica metodologicamente a desenvolver analogias visuais (mais diagramáticas e lógicas do que representacionais) para a segunda lei da Termodinâmica, e em particular para o conceito de entropia inerente a essa lei da perca irreversível de energia. Robert Smithson, como ele próprio explica numa entrevista a Paul Cummings (1972), interessou-se sempre pela origem e pelos começos primordiais também como forma de perceber e pensar o futuro em termos de obsolescência e de esquecimento ${ }^{31}$.

O futuro sem esquemas morais, sem plano e sem almas luminosas, apenas o retrocesso da evolução para o vazio. A organização (o aparecimento da massa terrestre, a sua estratificação geológica, o caldo biológico que originou a vida, as diferentes formas de vida e as ecologias que precederam a vida humana, $\mathrm{o}$ aparecimento desta, a tecnologia e a cultura que inventa a sua história, a estética, a arte), a totalidade multiplicada em inúmeras formas, intervalos temporais e fragmentos espaciais, a processar-se no sentido do seu próprio desaparecimento. A ideia de uma percepção da fisicalidade do espaço, em oposição a uma construção idealista do mesmo, relaciona-se com o interesse pessoal de Smithson pelas Ciências Terrestres e pela Geologia em particular. Enquanto a sua percepção dessa fisicalidade fundamenta-se num dado pré-humano, o objecto geológico, a sua ideia de entropia é explorada também a partir daquilo que é o processo de humanização, a interferência compositiva, organizadora da cultura humana (desde a agricultura, ao urbanismo, da economia à Land art). É esse elemento antropológico, essa possibilidade de uma analogia antropológica do problema

${ }^{31}$ No estudo que dedica a Robert Smithson (Robert Smithson, Unearthed-Drawings, collages, writings, New York: Columbia University Press, 1991) Eugenie Tsai, demonstra-nos que Robert Smithson possui um passado de interesses e de aprendizagens que é muito mais ecléctico do que aquilo que imaginaríamos. Os seus interesses não se subjugam apenas à linguagem teatral do Minimalismo e à subdivisão da Land Art. Encontramos um R.Smithson interessado pela ficção científica seja na sua forma filmíca seja na versão Comic Book; vêmo-lo a iniciar-se na cena artística nova-iorquina com uma pintura influenciada pela obra de Barnett Newman, pela fase She-wolf da pintura pollockianna, pelo brutismo de Dubuffett; vêmos um poeta, um ilustrador, um auto-didacta, etc. 
da entropia, que interessará a Gordon Matta-Clark. E será dessa possibilidade, (encontrar exemplos humanos da eternidade irreversível, da metabolização do existente em não-existente, do humano em mineral), que se alimentará a fase inicial da obra de G.M-C.

Mas, apesar do alinhamento com R. Smithson na questão da entropia, G.M-C faz uma réplica ao neo-primitivismo dos land-artists que "encontram na paisagem uma co-extensão da galeria de arte" ${ }^{32}$, e que transformam a Natureza no parque/laboratório temático das suas interrogações sobre o campo artístico; é que para o artista avançado ser realmente repercussivo tem que redefinir o conceito de Natureza nos finais do séc. XX, e isso implica regressar ao ambiente urbano, estudar o carácter finito, degenerativo, incompleto das maravilhas da modernização, reinterpretar os ciclos de produção/consumo dos seus objectos vivos ou moribundos; é neles que convergem e que vigoram as contradições da experiência humana, os sobressaltos históricos e políticos, é nas coisas de fabrico e uso humano que faz sentido estabelecer uma co-extensão com a galeria de arte.

As perfurações de estruturas arquitectónicas realizadas por Gordon Matta-Clark em ambientes premonitórios da era pós-fordista ${ }^{33}$, o seu filme Substrait (Underground Dailies) onde realiza uma descida prospectiva aos esgotos e subterrâneos da ilha de Manhatan, a sua aquisição de exíguos e inúteis lotes de terreno leiloado pela Cidade de Nova Iorque (Reality Properties: Fake estates, 1973); todas estas actividades podem, segundo a hipótese sugerida por Thomas Crow, ser inferidas como uma transferência do ethos filosófico dos projectos de Land Art para o espaço urbano e para a sua escala poluída, socialmente complicada e dependente da cultura automóvel. É como um movimento orgânico entre ar e terra, entre superfície e vazio, segurança (física, social) e perigo (de ferimento, de morte ou de prisão) realizado a partir de uma construção artificial incrustada nos mecanismos e inércias da burocracia e da propriedade. Gordon Matta-Clark coloca como pares e oponen1985

${ }^{32}$ Robert Smithson citado por Dan Graham no artigo Gordon Matta-Clark,

${ }^{33}$ Armazéns portuários abandonados como em Dead's End, 1975, edifícios de habitação e de escritórios condenados como em Threshole, Bronx, 1972-73, Bingo, Conical Intersect, Paris, 1975, Office Baroque, Antuérpia, 1977, fábricas seculares fechadas. 
tes o verticalismo clean-drawn das fachadas, a exposição do edifício e da arquitectura moderna ao inconsciente urbano e o horizontalismo subterrâneo, a parte orgânica e reprimida dos edifícios.

A escassa demografia que de facto visitou, muitas vezes com risco da sua segurança física senão da própria vida, as suas estruturas subtractivas deveu-se não só à natureza semi-clandestina quase sempre associada a entraves burocráticos e a apuros legais mas ao carácter absolutamente novo de a obra ser literalmente uma das etapas de um processo de decomposição que expunha o esqueleto estrutural, que fracturava os vigamentos, exumando o vazio entre os pisos (Bronx Floors,1972-73, por exemplo, ou Office Baroque, 1977) e ameaçando a sua função estrutural de suporte de cargas, isto é, a obra exacerbava o desaparecimento de um vazio que durante anos permanecera isolado, compartimentado entre telhado e cave. Se todas as operações para se chegar a esse ponto de não retorno implicavam um perigo eminente de colapso e de morte, fica então claro que a visita destes espaços não podia ter o carácter público e comunitário projectado por G.M-C: a hipótese de um acidente mortal colocaria a liberdade e o impulso artístico de G.M-C numa mais que certa situação de não-liberdade.

A ruína do edifício é intensificada pelo corte e pela subsequente adição de vazio. Mas ao mesmo tempo que o fim se torna irreversível a autopsia desse fim sobre expõe um facto incómodo: uma comunidade vertical dissolveu-se, as crianças já não sobem a correr pelas escadas, já não se ouvem os choros dos recém-nascidos ou os sobressaltos das discussões domésticas, nem se combinam encontros ao telefone, ou se houve música na rádio ou se vêem relatos desportivos na televisão, os risos, a alegria e a tristeza das famílias silenciou-se, fecharam-se negócios, toda a parafernália da vida doméstica ou do trabalho quotidiano desapareceu, atingiu o ponto do não retorno em que a memória perde ela própria consistência e utilidade. $\mathrm{O}$ escândalo produzido pelo Conical Intersect (1975) evidenciou essa mortalidade imposta que se esconde sob a camada estética que a modernidade nomeia de progresso.

Gordon Matta-Clark esforçou-se por nos demonstrar que um edifício não é só uma repartição e ordenação das partes, não é só uma presença inanimada mas o depósito de uma temporalidade secreta, de 
acontecimentos que ferem a sua sensibilidade. Um edifício é, mesmo na sua morte "(...) um lugar praticado. ${ }^{34 "}$

\section{Conical Intersect ou Etant d'Art pour locataire, 1975 ou Le dedans est un dehors}

"Completude através da remoção. Abstracção das superfícies. Não construir, Não reconstruir, não edificar espaço. Criar complexidade espacial, ler novas aberturas, contrastá-las com velhas superfícies. A luz admitida no espaço ou além das superfícies que são cortadas. Arrombar e invadir: aproximar-se do colapso estrutural, separar as partes até ao ponto do colapso."

GORDON MATTA-CLARK, $1971^{35}$

O termo Paralaxe refere-se a uma aparente mobilidade, um falso deslocamento do objecto observado provocada pela mudança de posição do observador, portanto, a uma alteração subjectiva do posicionamento de um objecto que se reporta não à natureza do objecto mas à do seu interlocutor/espectador; Hal Foster no seu texto The Return of the Real $(1993)^{36}$, propõe adoptar como processo metodológico este fenómeno perceptivo para reavaliar a experiência modernista mas é num texto do filósofo esloveno Slavoj Zizek ${ }^{37}$, Living in the end of times (2010) que encontramos o efeito paralaxe aplicado ao campo da arquitectura e onde este conceito adquire uma dimensão epistemológica para o observador e ontológica para o objecto observado ao inscrever este "deslocamento (...) no próprio edifício «real»-como se o edifício, na

\footnotetext{
${ }^{34}$ Michel de Certeau, Arte de Fazer- A invenção do quotidiano, Petrópolis: Vozex, 1998.p. 202.

${ }^{35}$ Gordon Matta-Clark, GMCA, Apud Thomas Crow, (2003), “(A survey on) Gordon Matta-Clark". In Corinne Diserens (Ed.), Gordon Matta-Clark. London: Phaidon, p. 33. p. xxii.

${ }^{36}$ Hal Foster, The return of the Real, Massachussets: The MIT Press, 1993,

${ }^{37}$ SLAVou Zizek, Viver no fim dos tempos, Lisboa: Relógio d'água, 2011, p. 301-302 .
} 
sua própria existência material, fosse portador da marca de perspectivas diferentes e mutuamente exclusivas ${ }^{38 "}$; Zizek caracteriza o desvio paraláctico como intrínseco à própria ideia de arquitectura, " significa, diz-nos, que a disposição espacial de um edifício não pode ser compreendida sem referência à dimensão temporal: o desvio paraláctico "é" a inscrição da nossa experiência temporal cambiante quando nos aproximamos de um edifício e entramos nele ${ }^{39}$ ", isto é, quando o sujeito desliga-se do patamar fotogénico em que os objectos são enquadrados como um ritual de exposição e de apresentação e adquirem uma implicação empírica, são sujeito e objecto de um activismo, estimulam o movimento e movem-se eles próprios numa hiperfragmentação de ocorrências espaciais. O desvio paraláctico é um mecanismo de exclusão que serve, contraditoriamente, a compreensão e identificação do impasse ideológico, que cerca o espaço arquitectónico; ele, o espaço arquitectónico, não é apenas um constructo social mas também um aparato tecnológico, não é apenas uma obra de arte (ou de anti-arte) mas um objecto/artefacto antropológico, não é apenas uma coisa do passado, uma artesania, mas um problema do presente pós-fordista, é um conceito que se transforma em mercadoria mas que também resiste à colonização da mercadoria; a forma nem sempre obedece à função, anula-a, mas esta nem sempre se dissocia da forma.

É este "deslocamento" que torna a forma (espacial, construída, arquitectónica) num estar em e num estar durante. Esta conjunção de cinética e tectónica desagrega a forma das outras formas que a envolvem e contextualizam, separa-a do todo; será esta ontologia do edifício que não o é apenas pelas suas funções (que pretensamente fixam a sua identidade, a sua mediaticidade) mas porque existe um sujeito, uma comunidade, que o pratica (por via do viver ou da memória, da passagem do tempo, da relação entre aqui-agora e ali-outrora); é este "mecanismo de exclusão" onde o espaço se torna estável e as suas formas são irreconhecíveis e tensionais que Gordon Mata-Clark explorou no seu projecto Conical Intersect.

Foi em Paris, mais precisamente no Plateau Beaubourg, em dois edifícios geminados do Séc.XVII, encostados ao nascente exo-esque-

\footnotetext{
${ }^{38}$ Slavou Zizek, Viver no fim dos...Cit., p.302.

${ }^{39}$ Slavoj ZizeK, Op. Cit., p.302.
} 
leto multifuncional do Centre Georges Pompidou, que Gordon Matta-Clark planeia e executa de 24 Setembro a 10 Outubro de 1975, num clima de contra-relógio, uma concavidade ocularcêntrica. As duas casas são sobreviventes, com os dias contados, do enorme processo de demolição que, desencadeado nos anos 30 e reforçado a partir da década de cinquenta com a inactivação do Mercado abastecedor das Halles, transformara todo o bairro no então famoso Trou des Halles (famosa depressão orográfica de fabrico humano definida pelo perímetro do recinto dos matadouros e do mercado e do bairro circunvizinho).

Gordon Matta-Clark realizará o seu projecto à custa, quase unicamente, dos instrumentos clássicos da força braçal: martelos, serras e picaretas. E manifestando, sem dúvida, uma convicção agonística capaz de compensar a pressão física, cortou, de dentro para fora, enormes porções de materiais parietais e de suporte, desenhando por via extractiva um orifício cónico inclinado $32 .^{\circ}$ graus em relação à parede lateral, que metabolizava o carácter mortuário e fugitivo daqueles dois lotes.

O espaço do Bairro des Halles era uma zona de transição e por isso indefinível. O Conical Intersect acentuará a violência dessa indefinição ao sobrepor à forma (que fecha, que contém) a superfície do vazio. $\mathrm{O}$ que é extraído, retirado, desmontado indetermina a fronteira entre o finito (o interior) e o infinito (o que está fora) mas o que se cria não é só um espaço transparente (o desocultamento do escondido, a revelação de uma nova camada de sentido no espaço improdutivo do que se tornou ruína) mas um espaço suspenso na sua negação, atraído para fora de si mesmo, convergindo para a potência arquivística e utilitária que é a rua. $\mathrm{O}$ velho bairro parisiense, proscrito de qualquer finalidade social, de qualquer hipótese de remissão, irremediavelmente embarcado na sua própria falência orgânica, entrava, através da metonímica desse novo espaço implosivo, o cone invisível, em comunicação directa com o processo auto-fágico e informe da modernização urbana em que o pó, a ausência, a desfiguração eram tropos convergentes.

O cone aéreo, que apenas se denota através de imagens secundárias (os cortes), é uma montra antinómica onde a amnésia, a não-imagem, a extinção em massa e a produção em massa se revelam factores decisivos e inescapáveis na produção social do ambiente urbano moderno. Foi talvez a mais expressiva realização do conceito de ruinment definido por Matta-Clark. E foi-o também pelo pathos auto-imune desse conceito em que a ideia de uma tectónica da ficção nacional é conju- 
gada com a consciência material do impermanente- de que nada dura. Assim a ruína suspende temporariamente a sua condição e torna-se o "espaço praticado" de uma ficção e o monumento anula-se aparecendo como uma experiência sobre o momento irreversível em que as coisas, as vidas e os valores deixam de o ser.

Mesmo para a percepção errática, sem grandes clarões filosóficos, incompleta do transeunte, que ao nível da rua, apenas vê nascer um buraco, que tem uma experiência pobre e repleta de intervalos na causalidade do acontecimento, que ignora o que realmente se está a passar, perdura um elemento de estranheza mas também de incredulidade pois aquele não é um lugar anónimo apesar da sua indefinição e aparente inutilidade; aquele espaço tem uma entrada e uma saída na história e no quotidiano recente da cidade, e ainda que se integrando na categoria definida por Robert Smithson para descrever alguns constituintes tipológicos do subúrbio americano, (em particular os parques de estacionamento, e o Trou foi durante muito tempo um parque de estacionamento) como uma imensa entidade negativa informe, não é um ermo sequer um depósito do passado não histórico. A história socialmente complicada do lugar contra-ataca a interrupção abstracto-geométrica do cone. O activismo artístico de G.M-C e o seu produto foram, sobretudo na esquerda política francesa, interpretados como um grande disparate; uma caricatura infeliz que celebrava a industrialização da expropriação e também, por via do argumento de que o buraco é arte, a naturalização da cultura do múltiplo em que o espaço reaparece sem vida, sem eternidade, reaparece limpo de toda as contracções antropológicas e sociais, de todas as marcas digitais. $\mathrm{O}$ "x" incógnito não marca o lugar apenas oculta os seus cadáveres.

Ettant Donné foi em muitos aspectos um exercício sumativo dos seus ensaios extractivos nova-iorquinos repletos de dissabores legais, de incompreensões sobre a finalidade da sua técnica de apropriação e transformação do espaço construído; ensaios que se fizeram em torno da liberdade como consciência e verificação do limite e do proibido. É um acto de fronteira entre o que nasce e ainda é inapreensível, (o futuro centro Beaubourg desenhado por Renzo Piano e Richard Rogers ainda num estado pré-natal) e a materialidade de um lacónico edifício seiscentista que cessou a sua condição temporal e se encontrava destituído de vida civil e de vínculos antropológicos. 
Nas inúmeras fotografias com que Gordon Matta-Clark reportou o seu processo aventuroso de trabalho e o saldo final do seu situation-specific parisiense observamos por vezes o óculo cónico inquirindo a rua e integrando-a no espaço-tempo do edifício moribundo. O gesto irreversível, excisor coloca em coexistência dinâmica e poética um domicílio-cadáver e a cidade que o abandona. Um condensador social inesperado e sem precedentes que coloca em acção simultânea o evento artístico, a problemática social da renovação urbana, os limites comunicacionais dos objectos artísticos e públicos, e a visualidade pura. 